\title{
RELIGIÃO, POLÍTICA E EDUCAÇÃO: MAGNO MALTA E O PROJETO DE LEI ESCOLA SEM PARTIDO
}

\author{
RELIGION, POLICY AND EDUCATION: MAGNO MALTA AND THE DRAFT SCHOOL LAW
}

Marcos Vinicius de Freitas Reis
\[ \begin{array}{c}\text { http://lattes.cnpq.br/0706355533898912 } \\ \underline{\text { https://orcid.org/0000-0002-0380-3007 }}\end{array} \]

$\begin{array}{r}\text { Yuri Lima Pinheiro } \\ \text { http://lattes.cnpq.br/3291091938974380 } \\ \hline \text { https://orcid.org/0000-0002-9714-2245 }\end{array}$

Recebido em 21 de janeiro de 2020.

Aprovado em 17 de março de 2020.

\begin{abstract}
RESUMO: No decorrer da história da educação brasileira, percebe-se que a mesma esteve ligada de forma significativa ao elemento religioso desde o seu princípio. Tal influência foi adquirindo diferentes formas e com predominância inicial da igreja católica, até chegarmos à segunda metade do século XX, quando o crescimento dos evangélicos mudou os rumos da sociedade e possibilitou uma ampliação do seu espectro de ação, envolvendo inclusive o campo político. Nesse sentido, o ex-senador Magno Malta surge como um importante personagem, fruto dessa maior representatividade, atuando em prol da defesa de ideias conservadoras e antidemocráticas, materializadas na criação do Projeto de Lei (PL) Escola Sem Partido. Assim, o presente artigo se baseará em uma pesquisa documental, com posterior análise de conteúdo conforme Bardin (2002) e Moraes (1999), com enfoque nos argumentos do então senador para defender o PL e seu posicionamento, tendo em vista que tal proposta de alteração nas Leis de Diretrizes e Bases da Educação Nacional desafia diretamente aspectos relacionados ao respeito à diversidade, laicidade e pluralidade e traz à tona a necessidade da luta constante por uma educação libertadora.

Palavras-chave: educação, religião, política, Escola Sem Partido, Magno Malta
\end{abstract}

\begin{abstract}
Throughout the history of Brazilian education, it is clear that it has been linked significantly to the religious element since its inception. This influence took on different forms and with an initial predominance of the Catholic Church, until we reached the second half of the twentieth century, when the growth of evangelicals changed the direction of society and enabled an expansion of its spectrum of action, including even the political field. In this sense, ex-senator Magno Malta emerges as an important character, the result of this greater representativeness, acting in favor of the defense of conservative and anti-democratic ideas, materialized in the creation of the Law Project (PL) Escola Sem Partido. Thus, the present article will be based on a documentary research, with subsequent content analysis according to Bardin (2002) and Moraes (1999), focusing on
\end{abstract}

${ }^{1}$ Docente do Curso de Mestrado Acadêmico em História Social da UNIFAP. Docente do Curso de Mestrado Profissional Ensino de História UNIFAP. Doutor em Sociologia pela Universidade Federal de São Carlos. Líder do Centro de Estudos Políticos, Religião e Sociedade na Amazônia (CEPRES). E-mail: marcosvinicius5@yahoo.com.br

2 Acadêmico do Curso de Licenciatura em Sociologia da Universidade Federal do Amapá. E-mail: ylimapinheiro@gmail. $\underline{\mathrm{com}}$ 
the arguments of the then senator to defend the PL and its position, considering that such proposal of The change in the National Education Guidelines and Bases Laws directly challenges aspects related to respect for diversity, secularity and plurality and brings to light the need for the constant struggle for a liberating education.

Key-Words: education, religion, politics, Partyless School, Magno Malta

\section{INTRODUÇÃO}

$\mathrm{Na}$ historiografia e na contemporaneidade, os campos religioso, político e educacional sempre possuíram suma importância e despertaram em determinados grupos sociais o sentimento de disputa. Dessa forma, percebe-se na segunda metade do século XX que o Brasil, que tinha em sua maioria uma população cristã católica, passou também a ser cenário do crescimento de um outro grupo de cristãos: os evangélicos. Devido a isso, os evangélicos - em especial os Pentecostais - dedicaram-se a conquistar espaços na política, começando com atuações singulares até atingirem o status de bancada partidária.

Desse modo, é essencial salientar que a atuação dos evangélicos no cenário político resultou em propostas que representam o interesse desse grupo social e diversos setores da sociedade. Nesse contexto, surge na década de 1990, a atuação política de Magno Pereira Malta. Natural de Macarani (BA), Magno Malta é pastor evangélico, formado em teologia pelo Seminário Teológico Batista do Norte do Brasil (STBNB)e exerceu os mandatos de vereador (1993-1994) deputado estadual (1995-1998) deputado federal (1999-2002) e senador por dois mandatos (2003-2018). Vale ressaltar, que o próprio ex-senador, intitulava-se como defensor de "bandeiras humanitárias e cristãs” e comandava a Frente Parlamentar Mista em Defesa da Família, o que o credenciava como líder de parte de um grupo de parlamentares cristãos.

Devido à atuação ativa e propositiva de Magno Malta, principalmente no Senado Federal, nos debruçaremos neste artigo em uma de suas propostas direcionadas ao campo educacional: o Projeto de Lei (PL) Escola sem Partido. O PL n. ${ }^{\circ}$ 193/2016 apresentado ao Senado Federal consistia na inclusão do Programa Escola Sem Partido entre as diretrizes e bases que orientam o funcionamento da educação nacional (LDB), conforme a Lei n. ${ }^{\circ}$ 9.394, de dezembro de 1996 (SENADO FEDERAL, 2016, p 32; GUILHERME, PICOLI, 2018, p 54).

Nesse sentido, partimos da seguinte questão: quais as razões que levaram o então Senador Magno Malta a propor o Projeto de Lei Escola Sem Partido? Dessa forma, analisaremos os principais argumentos utilizados por Magno Malta em defesa do referido Projeto de Lei, no intuito de compreender seu posicionamento político. É imperativo registrar que o referido Projeto de Lei, proposto no ano de 2016, foi um dos PL de maior repercussão nos meios de comunicação, gerando muitas discussões na sociedade. Como consequência, o site do Senado Federal realizou consulta pública com quase 2 meses de duração que obteve a participação de mais 400 mil pessoas, na qual a maioria votou contra a implantação do programa, com 199.873 votos a favor e 210.810 votos contra o Programa ESP (E-CIDADANIA, 2016, p30; GUILHERME, PICOLI; 2018, p57 ).

É preciso, porém, reconhecer, que a criação de um projeto de lei como esse, que buscava uma expressiva inclusão na LDB é a materialização das ideias defendidas pelo Movimento Escola Sem Partido (MESP). O MESP foi criado em 2004 no Brasil pelo advogado Miguel Nagib, que na época era procurador do estado de São Paulo. Esse movimento consiste em uma iniciativa de pais e alunos com o intuito de impedir a ocorrência do que denominam "doutrinação política" nas escolas em todos os níveis de ensino, assim como inspecionar e 
fiscalizar as práticas docentes desenvolvidas no ambiente escolar e os materiais didáticos utilizados pelos alunos em busca de qualquer indício de "doutrinação ideológica", como o debate a respeito de temas como gênero, sexualidade e religião (FERREIRA, ALVADIA FILHO; 2017, p 67 ; EDUCATIVA, 2016, p 38).

Com efeito, para relacionarmos todos esses fatos socais no artigo, adotamos o seguinte caminho metodológico: a pesquisa se configurou como documental, buscando material para análise tendo como sujeito Magno Malta. Ademais, foi realizado um estudo baseado na análise de conteúdo dos argumentos utilizados pelo então senador em defesa do Projeto de Lei Escola Sem Partido, utilizando como fontes o texto do referido projeto ( $\mathrm{n}^{\mathrm{o}} 193$ de 2016), os endereços eletrônicos oficiais do Movimento Escola Sem Partido (http://www.escolasempartido.org/ https://www.programaescolasempartido.org) e vídeos obtidos na plataforma YouTube após realizar busca com os descritores "Magno Malta defendendo o projeto de Lei Escola sem Partido". Para isso, as informações foram organizadas conforme descrito por Bardin (2002) e Moraes (1999), com o objetivo de identificar e discutir os principais pontos favoráveis ao projeto presentes nos argumentos desse político

Para tanto, o artigo encontra-se dividido em três etapas distintas e ao mesmo tempo interrelacionadas. Na primeira, abordamos a história da educação brasileira, que esteve atrelada de forma recorrente ao elemento religioso, tendo em vista a relação de Igreja Católica e Estado no primeiro momento e o crescimento dos evangélicos posteriormente, acompanhado de suas propostas para educação. Dessa forma, relacionamos esses fatos às concepções de laicidade, diversidade religiosa e pluralismo de ideias. Na segunda etapa, foi analisada a entrada dos Evangélicos no campo político, que se fortalece na década de 1980 até atingirem o status de bancada evangélica. Inegavelmente, será possível compreender que estes grupos como bancadas dialogam com os governos, conquistam espaços e trazem uma base religiosa e moral para o aspecto público. Por fim, na terceira etapa, abordamos o Projeto de Lei Escola sem Partido de autoria de Magno Malta, em conjunto dos argumentos utilizados pelo referido político para defender o PL, e assim defender o seu posicionamento em torno da necessidade de implantação do Programa Escola Sem Partido.

\section{HISTÓRIA DA EDUCAÇÃO BRASILEIRA}

\subsection{EDUCAÇÃO BRASILEIRA E O ELEMENTO RELIGIOSO}

Em primeiro plano, é importante compreendermos através do olhar histórico que a religião no Brasil sempre participou de forma direta ou indireta do campo educacional. É evidente que estamos falando primordialmente da Igreja Católica, que esteve atuando na educação desde a chegada dos portugueses e permaneceu por muito tempo, inclusive tendo sua presença legitimada por meios legais, como as Constituições. Dessa forma, faremos uma breve contextualização da história da educação brasileira ligada ao elemento religioso.

Observa-se, desse modo, que imediatamente após a chegada dos colonizadores no Brasil, religiosos formados pela Companhia de Jesus realizaram um trabalho pedagógico e missionário com o povo. Esse trabalho tinha como intuito garantir segurança da unidade política, já que uniformizava a fé e a consciência das pessoas. Concomitantemente a isso, há indícios de que as primeiras escolas fundadas aqui por padres jesuítas atendiam unicamente à elite, que na época, era representada pelos filhos dos senhores de engenho, enquanto aos filhos de colonos 
e índios, por exemplo, ensinava-se um ofício e divulgava-se a fé católica, não permitindo qualquer chance de desenvolvimento de uma educação popular (CUNHA, BARBOSA, 2011 p 67).

Nesse sentido, durante um significativo período, esse modelo de educação predominou em nossas terras, exercendo o monopólio do ensino com o apoio da Coroa de Portugal. Posteriormente, todavia, o governo percebeu que a educação jesuítica já estava estruturada, com muitas escolas, dotada de organização e hierarquia e por conta disso, tomou a decisão de encerrar as atividades da Companhia de Jesus para não correr o risco de perder seu poder e domínio econômico e político (ARANHA, 1996 apud CUNHA, BARBOSA, 2011, p 60). Inicia-se, portanto, a partir da expulsão dos jesuítas, a construção de outro modelo de sistema educacional, onde o Estado assumiu pela primeira vez a promoção da educação (CUNHA, BARBOSA, 2011, p60).

Cabe reconhecer, no entanto, que apesar do rompimento com os jesuítas, o novo modelo de sistema educacional que o Estado começava a construir não se propõe de imediato a promover uma educação popular, repleta de valores democráticos, que respeitasse a cultura de indígenas e negros. Ao contrário disso, nota-se que até determinado período, a ligação entre essas instituições ganha uma nova legitimidade através das Constituições que são elaboradas, permitindo a manutenção da presença da Igreja Católica na Educação Brasileira. Em decorrência disso, a primeira Constituição Brasileira outorgada em 1824, por D. Pedro I, juntamente com documentos complementares do Brasil Império, determina o ensino da religião católica nas escolas (CUNHA, BARBOSA, 2011 p 78).

Seria um erro, contudo, esquecer que posteriormente, a Constituição Brasileira de 1891, trouxe ao debate a separação legal entre Estado e Igreja, o que implicou na presença do ensino leigo ministrado em estabelecimentos públicos (BRASIL, 1891). Dessa forma, é no Brasil República que se inicia no campo teórico uma aproximação com a laicidade e que a proposta de um ensino confessional ligada a uma única visão de mundo católica passa a ser questionada.

Após esse período, já na Constituição de 1934, o Ensino Religioso é constituído como matéria nas escolas públicas, com frequência facultativa, porém de acordo com os princípios da confissão religiosa do aluno manifestada pelos pais ou responsáveis. $\mathrm{Na}$ Constituição de 1937, no governo de Getúlio Vargas, o Ensino Religioso está presente, mas não consta como disciplina obrigatória nas escolas. Diferentemente do Estado Novo, nas duas Constituições Brasileiras seguintes - 1947 e 1967 - o que se percebe é a manutenção do Ensino Religioso nas escolas, sendo sua oferta obrigatória, mas sua matrícula facultativa. Apesar da introdução da matéria de Ensino Religioso nas escolas, o que poderia ser um ganho significativo para a promoção do respeito e tolerância, o professor que ministrava a matéria ingressava na carreira do magistério através de indicação de uma autoridade religiosa, o que consequentemente ainda ligava esses ensinos à confissão de fé religiosa (CUNHA, BARBOSA, 2011, p 45).

Em detrimento dessa questão, é a partir da Constituição de 1988, que valores da república como a cidadania, a dignidade da pessoa humana e a liberdade religiosa caminham do campo teórico para uma experiência maior no campo prático, ou seja, o campo da realidade social. Impulsionado por esse novo momento, temos a frente a aprovação da Lei de Diretrizes e Bases da Educação, lei no 9.394/96, que no ano seguinte, traz uma modificação referente ao ensino religioso que nos chama a atenção: 
O ensino religioso, de matrícula facultativa, é parte integrante da formação básica do cidadão e constitui disciplina dos horários normais das escolas públicas do ensino fundamental, assegurado o respeito à diversidade cultural e religiosa do Brasil, vedadas quaisquer formas de proselitismo (FEDERAL, 2005, p. 18).

A partir dessas novas leis o Ensino Religioso passa a integrar o sistema de ensino, sendo uma matéria capaz de trabalhar a religião como um fenômeno social, e através disso, contribuir socialmente com a promoção da tolerância religiosa e respeito à diversidade. Seria possível então que, neste novo momento histórico, após ter superado a colonização, a escravidão e ditaduras, o Brasil, por meio de valores democráticos, tivesse um ensino público laico, ou seja, um ensino separado da influência dos poderes eclesiásticos e de toda referência e legitimação religiosa (MARIANO, 2011 p 34). Todavia, é paralelo a todos esses fatos sociais que temos, na segunda metade do século XX, mudanças significativas no campo religioso brasileiro. Trata-se do crescimento da população de confissão evangélica, especialmente os Pentecostais, e, de outro lado, a queda dos católicos da população de confissão católica. Dessa forma, trabalharemos no tópico a seguir como esses fatores puderam ganhar forças na sociedade e consequentemente trazer à tona uma reinvindicação de pautas para o campo educacional brasileiro.

\subsection{CAMPO RELIGIOSO BRASILEIRO E PROPOSTAS PARA EDUCAÇÃO}

O contexto social a partir de 1960, adentrando o século XXI, mostra-nos que ocorreu no Brasil significativa mudança no campo religioso. Não se trata de uma queda dos cristãos católicos capaz de tirá-los a hegemonia de fiéis no país, mas de alterações nesse campo suficientes para estabelecer novos concorrentes. Desse modo, os dados do Censo Demográfico provam que entre 1980 a 2010, os católicos declinaram de 89,2\% para 64,6\% da população, totalizando uma queda de 24,6\%, enquanto os evangélicos saltaram de 6,6\% para 22,2\% (MARIANO, 2013, p 34). Existem dados do IBGE/Sidra sobre o tema]Nesse sentido, Ricardo Mariano nos diz que:

A rápida redução do peso da hegemonia católica no país decorreu diretamente, mas não exclusivamente, do crescimento acelerado de seus concorrentes religiosos, sobretudo das igrejas pentecostais (...). A expansão dos demais grupos religiosos minoritários pesou muito pouco para o declínio do catolicismo. De modo que a desmonopolização e a destradicionalização religiosas estão associadas à pluralização religiosa e à intensificação da concorrência no e por mercado religioso (...). Não deixa de ser curioso que em plenos anos 80 , justamente no momento da arrancada desse processo de destradicionalização, pluralização e concorrência religiosa, o clero católico ainda se mantivesse ferreamente convicto na existência de uma indissolúvel "aliança mística Igreja-Nação" (MARIANO, 2013, p. 120)

Fica claro, dessa forma, que a filiação religiosa estava ligeiramente desligando-se da ideia de ser considerada uma herança familiar, que ocorria de forma automática e irrefletida, para ser considerada livre escolha individual, uma opção consciente de caráter pessoal e subjetiva (MARIANO, 2013, p32). Com efeito, já no século XXI, especificamente em sua primeira década, nota-se que os evangélicos cresceram cinco vezes a mais do que a população brasileira: $61,4 \%$ contra 12,3\%, o que resultou em um aumento de 16 milhões de adeptos (MARIANO, 2013, 
p32). Evidencia-se, portanto, que o contexto brasileiro de redemocratização, de autonomia para tomar decisões e de diversidade, favoreceu o crescimento dos evangélicos que não apenas avançaram numericamente, mas estruturaram-se na sociedade com status de protagonistas.

É primordial compreender que os evangélicos nesse cenário, especialmente os pentecostais, adotam uma postura proselitista no seu convívio social, o que implica no empenho de convencer outros grupos sociais à determinada ideia, diretamente ligada à sua religião. Dessa forma, a cidadania desses evangélicos não é sinônimo de anonimato ou de identidade social de caráter nivelador e igualitário. Ao contrário disso, uma parcela significativa dos evangélicos constrói sua cidadania no espaço público estreitamente vinculada à identidade particular, que no campo ideal, deveria permanecer apenas no espaço privado (GRUMAN, 2005, p30). Diante dessa problemática, constata-se que o campo social brasileiro foi solo fértil para que grupos evangélicos, de forma organizada e estruturada, começassem a sugerir propostas para determinadas áreas públicas. Sendo assim, o campo educacional não passou ileso a essas propostas, tendo em vista que no ano de 2004 nasce o Movimento Escola Sem Partido.

É essencial ressaltar que o Movimento Escola Sem Partido (MESP) é uma das principais propostas de grupos conservadores como os evangélicos para a educação brasileira. Inspirado em um projeto desenvolvido nos Estados Unidos, o NoIndoctrination.org, o MESP consiste em uma iniciativa de pais e alunos com o intuito de impedir a ocorrência de "doutrinação política" nas escolas em todos os níveis de ensino. Além disso, conforme o que pode ser encontrado no site da organização (Escolasempartido.org), o Movimento Escola sem Partido é independente, sem fins lucrativos e se declara sem qualquer vinculação política, ideológica ou partidária. Ademais, o objetivo do MESP é promover a luta pela "descontaminação e desmonopolização política e ideológica das escolas", pelo "respeito à integridade intelectual e moral dos estudantes" e pelo "direito dos pais de dar aos seus filhos a educação moral que esteja de acordo com suas próprias convicções" (ESP, 2017,p 78).

O MESP é coordenado, desde a sua criação em 2004, pelo advogado brasileiro Miguel Nagib, que na época era procurador do estado de São Paulo. Em entrevista realizada pela Revista Profissão Mestre em agosto de 2016 e divulgada no site do projeto, Nagib explica que o movimento se iniciou como resposta à "instrumentalização do ensino para fins político-ideológicos, partidários e eleitorais" (ESP, 2017). Torna-se, evidente, portanto, o alinhamento do Movimento Escola Sem Partido ao pensamento conservador que vem crescendo no Brasil, bem como a movimentos de repúdio à, recebendo apoio da bancada evangélica, de defensores da "cura gay", políticos a favor da pena de morte, simpatizantes da ditadura militar, entre outros presentes nessa visão política (SARAIVA, VARGAS, 2017, p 43).

Sobre essa questão, Manhas (2016, p 34), manifesta-se da maneira apresentada abaixo:

Os teóricos do Escola Sem Partido advogam a neutralidade e se dizem não partidários. No entanto, suas intenções são claras: a retroação dos avanços que tivemos nos últimos tempos, especialmente com relação aos direitos humanos. Por exemplo, quando dizem lutar contra a doutrinação, uma das situações apresentadas no site do movimento é um seminário realizado pela Comissão de Educação da Câmara dos Deputados sobre direitos LGBTI e a política de educação. Eles citam esse caso como uma afronta ao artigo 12 da Convenção Americana sobre Direitos Humanos, afirmando que pais e seus filhos têm que ter uma educação moral de acordo com suas convicções. É uma deturpação do citado artigo, que diz respeito à liberdade religiosa que deve ser respeitada individualmente. Além disso, manipulam e fazem confusão deliberada com a discussão realizada no seminário, que reafirmou a importância de se debater questões de 
gênero e sexualidade nas escolas, para que as diferenças não sejam transformadas em desigualdades (MANHAS, 2016, p.18)

Nesse sentido, apesar de pregar o fim de ideologias e partidarização nas escolas, principalmente por parte dos professores, e de se declarar sem vínculos políticos e ideológicos, em 2015 o MESP uniu-se a diversas outras organizações conhecidamente de direita, entre eles o Movimento Brasil Livre (MBL) e Revoltados Online, para reivindicar e protestar, nas ruas e em suas páginas na internet, em favor do Impeachment da então Presidenta reeleita em 2014 pelo Partido do Trabalhadores (PT), Dilma Rousseff. Nessa perspectiva, também é válido relembrar que os participantes do MESP expressaram o apoio ao governo de Michel Temer, do Partido do Movimento Democrático Brasileiro (PMDB) - atualmente MDB -, sucessor de Rousseff na presidência (EDUCATIVA, 2016, p 35). Além disso, seus apoiadores defendem a aprovação de leis que proíbem a discussão de questões referentes a causas da população LGBTI (Lésbicas, gays, bissexuais, travestis, transexuais e intersexuais), desigualdades de gênero, sexualidade, raça e outras relacionadas aos direitos humanos (CARREIRA, 2016, p 45).

Torna-se evidente, portanto, que a postura assumida pelo MESP é totalmente contrária à pluralidade de ideias, questões de gênero e diversidade cultural e religiosa. O movimento ataca todas as ideias progressistas que se pensam para uma nação, dedicando ataques específicos ao campo educacional. Desse modo, é claro que a postura do movimento é uma reação à proposta de educação para o Brasil que passa a ser pensada e construída a partir da redemocratização. Não é fortuito que tenham elegido como algoz a Paulo Freire que destacava a importância de uma educação libertadora, que valorizasse na construção do ensino a criticidade, a ética e o respeito aos saberes e vivências do educando (FREIRE, 1996, p 90).

Contudo, é preciso admitir que mesmo com a atuação de teóricos do campo educacional e de uma parte da sociedade, que defendem até os dias atuais uma educação democrática, o MESP utilizou-se de estratégias que os fizeram crescer em todo o Brasil. Nesse sentido, foi conquistando espaços no campo político através de simpatizantes da causa, de bancadas partidárias - como a evangélica - que o movimento passou a propor suas ideias através de Projetos de Lei em Câmaras Legislativas Municipais, Estaduais, até chegar com vigor no Congresso Nacional. Para que se entenda melhor como esses fenômenos ocorrem, é necessário que se faça uma abordagem histórica que mostre como as bancadas evangélicas cresceram no Brasil a partir dos anos 1980 e como, consequentemente, atores políticos surgem nesse contexto como defensores de pautas conservadoras e antidemocráticas.

\section{CAMPO POLÍTICO BRASILEIRO}

\subsection{ENTRADA DOS EVANGÉLICOS NA POLÍTICA}

Ao tratar de religião e política no contexto brasileiro é natural remetermos à presença da bancada evangélica e católica. A ideia de bancada surgiu com a redemocratização no final dos anos 1980. Freston (1993, p 300) diz que após a finalização da Constituinte, as instituições religiosas Igreja Universal do Reino de Deus, Igreja Assembleia de Deus, Igreja Quadrangular e outras iniciaram a militância para eleger representantes para cargos executivo e legislativo.

Nesse sentido, Fonseca (2002, p 123) disserta sobre as razões que motivaram os grupos evangélicos a entrarem na política partidária. Uma das razões é o fato de não aceitarem que 
apenas a Igreja Católica tenha os benefícios do Estado, como, por exemplo, os feriados religiosos, investimentos públicos em obras sociais administradas por instituições religiosas, influência nas políticas educacionais e de segurança pública, dentre outros interesses. Além disso, há um entendimento por parte de segmentos deste grupo religioso que os princípios cristãos precisam ser obrigatoriamente os fundamentos da república.

Gruman (2005, p56) aponta que o voto e a cidadania são ressignificados por alguns setores pentecostais e neopentecostais. Dessa forma, votar implica expulsar ou evitar a presença do demônio na política brasileira, sendo o voto sinônimo de sacralização da política no combate a políticos ou gestores que não comungam com os princípios evangélicos e a cidadania um valor voltado para atender as demandas das instituições religiosas e de seus líderes, não objetivando o desenvolvimento de políticas públicas direcionadas para o bem comum postura que acena com a ruptura democrática e o autoritarismo.

Diante desse cenário, Py e Reis (2015, p 67) destacam que para conseguir eleger o maior número de parlamentares, os evangélicos investem em estratégias para profissionalizar tal prática como a exposição dos seus candidatos em meios de comunicação e apoio a políticos que sejam conhecidos do grande público evangélico em função de suas atividades religiosas. Sendo assim, os partidos escolhidos para lançar candidatos são agremiações controladas por religiosos ou figuras públicas do espectro político de direita ou centro-direita. Ademais, observa-se que muitos líderes evangélicos trabalham em suas igrejas como cabos eleitorais. Ou seja, o candidato escolhido pela cúpula da igreja, passa a ter o apoio institucional, financeiro e midiático dos grupos religiosos evangélicos.

Em decorrência disso, a atuação dos parlamentares da bancada evangélica pauta-se na defesa de valores conservadores. Não são raros os projetos de lei que são contrários à legalização da maconha, ao casamento gay e à adoção de crianças por casais homoafetivos seria útil enumerar exemplos desses casos ainda que em nota de rodapé. Por outro lado, defendem o ensino religioso confessional, a atuação mais agressiva das polícias em torno da questão da segurança pública, a volta do voto impresso e financiamento público na construção de igrejas ou empreendimentos ligados às instituições religiosas, dentre outros.

Fica claro, dessa forma, que a consolidação da bancada evangélica resulta em mudanças significativas no cenário político brasileiro. Por conseguinte, para o presidente da república aprovar algum projeto de lei, é necessário obrigatoriamente negociar com a referida bancada para se obter êxito. Sendo assim, a influência que os evangélicos exercem na política perpassa por negociações envolvendo cargos dentro do governo, proposições de projetos e posicionamento incisivo em todas as ações do governo executivo.

\subsection{ATUAÇÃO POLÍTICA DE MAGNO MALTA}

Dentro desse contexto de expansão do número de evangélicos e da sua maior participação no cenário político, o que culminou com o consequente surgimento da bancada evangélica, Magno Malta emergiu como um dos principais representantes desse grupo, assumindo um papel de grande notoriedade pública. Dessa forma, torna-se fundamental compreender sua trajetória, ideias e proposições mais relevantes, tendo em vista que elas materializam os valores defendidos por uma parcela significativa da sociedade.

Magno Pereira Malta nasceu em 16/10/1957, na cidade de Macarani (Bahia), é pastor evangélico, músico e graduado em Teologia pelo Seminário Teológico Batista Norte do Brasil 
(SENADO FEDERAL, 2019; AGÊECIA SENADO, 2015). Ele iniciou sua carreira política em 1992, ao ser eleito como vereador pelo município de Cachoeiro de Itapemirim (ES). No ano de 1994, elegeu-se deputado estadual pelo Partido Trabalhista Brasileiro (PTB), com 10.997 votos, enquanto em 1998 tornou-se deputado federal do Estado do Espírito Santo com 54.754 votos pelo mesmo partido. Mais adiante, concorreu ao cargo de Senador pelo Partido Liberal (PL) em 2002, sendo eleito com votação expressiva de 867.434 votos (FGV, 2015).

Foi no decorrer de sua trajetória política como senador que apresentou maior visibilidade e maior impacto em nível nacional, defendendo, entre várias causas, o endurecimento da legislação penal e redução da maioridade penal, além de se colocar contra o projeto de que pretendia criminalizar a homofobia em 2007 - quando já era filiado ao Partido da República (PR) - e contra propostas de revisão da legislação do aborto. Além disso, participou como suplente ou titular por vários anos da Comissão de Direitos Humanos e Legislação Participativa (2003-2018); entretanto, percebe-se que contraditoriamente, Magno Malta teve uma atuação que frequentemente violava alguns princípios dos direitos humanos, valorizando grupos específicos e atuando de forma contrária aos que divergiam dos seus próprios valores (AGÊNCIA SENADO, 2015; FGV, 2015).

Tal atuação em torno de temas como gênero, diversidade e educação, é evidenciada pela autoria de vários projetos de decreto legislativo relacionados a habilitação, celebração de casamento civil ou de conversão de união estável em casamento entre pessoas do mesmo sexo (PDS 106/2013), assumindo posição contrária ao estabelecido na Resolução no 175, de 2013. Além disso, propôs Projetos de Lei como o PLS 193/2016, com o objetivo de incluir entre as diretrizes e bases da educação nacional o "Programa Escola sem Partido", alteração de decreto-lei do código penal para criminalizar o aborto em qualquer fase da gestação (PLS 46/2017), além do PL que buscava alterar lei do Estatuto da Criança e do Adolescente para vedar o acesso de crianças e adolescentes a exibições artísticas consideradas inadequadas (PLS 506/2017) (SENADO FEDERAL, 2019).

É importante ressaltar que o posicionamento de Malta dialoga com o defendido por outras lideranças evangélicas, que diante da proposta de criminalização da homofobia, por exemplo, representaram uma importante resistência, acreditando que a proposição viola o direito à liberdade de expressão (AGÊNCIA SENADO, 2014). Além disso, é essencial compreender a influência do Movimento Escola sem Partido, já de caráter abrangente e fortalecido entre essas lideranças, para a criação do Projeto de Lei Escola Sem Partido, tendo em vista os diversos pontos convergentes entre os dois.

Chegando ao ano de 2010, Magno Malta se candidatou à reeleição pelo PR, recebendo votação ainda mais significativa diante de sua maior popularidade, com um total de 1.285.177 votos. Contudo, já em 2018, ficou em terceiro lugar nas eleições para senador, com 611.284 votos, atrás de Fabiano Contarato (REDE) e Marcos do Val (PPS), o que impossibilitou sua continuidade no Senado Federal (G1, 2010; G1, 2018). Mas, deve-se destacar que tal fato não representou o fim de sua influência e articulação no cenário atual, tendo em vista que Magno Malta permanece atuando, por meio de outras formas ou seja, sua rede de influências, como uma figura pública que defende as ideias e medidas previamente discutidas.

\section{O PROJETO DE LEI ESCOLA SEM PARTIDO: PERSPECTIVAS E INTERPRETAÇÕES POSSÍVEIS}


Como uma proposta de intervenção que buscava ter alcance nacional no campo educacional, o PL n. ${ }^{o}$ 193/2016 apresentado ao Senado Federal pelo então senador pelo estado do Espírito Santo, eleito pelo Partido da República (PR), Magno Pereira Malta, consistia na inclusão do Programa Escola Sem Partido entre as diretrizes e bases que orientam o funcionamento da educação nacional, conforme a Lei n. ${ }^{\circ}$ 9.394, de dezembro de 1996 (SENADO FEDERAL, 2016; GUILHERME, PICOLI, 2018, p89).

O PL n. ${ }^{\circ}$ 193/2016, com a implantação do Programa ESP, visava estabelecer alguns princípios que a educação nacional deveria atender, como neutralidade política e ideológica, liberdade de crença e de consciência, bem como a liberdade de aprender e ensinar, o entendimento do estudante como indivíduo vulnerável no contexto da sala de aula, entre outros (SENADO FEDERAL, 2016).

É possível observar que especial atenção é atribuída à questão do ensino de educação sexual nas escolas, haja vista que se encontra no documento a proposição da proibição de tratar o assunto "ideologia de gênero" nas escolas (SENADO FEDERAL, 2016). Essa determinação, no entanto, parece ir de encontro ao que está especificado no Artigo $2^{\circ}$ do PL, que inclui o pluralismo de ideias no ambiente acadêmico como um dos princípios a ser aplicado na educação nacional.

Ademais, o PL de autoria de Magno Malta visa a implantação em salas de aula e salas dos professores de cartazes informando os deveres dos professores estabelecidos pelo movimento Escola Sem Partido e a criação de um canal de comunicação para fins de denúncias e reclamações pelo Ministério e Secretarias de Educação, entre outras disposições (SENADO FEDERAL, 2016).

Entre as justificativas utilizadas para a elaboração do PL e, consequentemente, para a adoção do programa nas escolas brasileiras, observa-se a afirmativa de que "todos os que passaram pelo sistema de ensino nos últimos 20 ou 30 anos" vivenciaram a experiência de ver seus professores e livros didáticos e outros materiais apoiarem e ensinarem determinadas correntes ideológicas e também políticas, com o intuito de fazer com que os estudantes adotassem essas visões de mundo, principalmente no que tange ao aspecto moral sexual (SENADO FEDERAL, 2016).

Assim, de acordo com o texto do PL, os professores abusam da liberdade de ensinar liberdade de cátedra, haja vista que estão manipulando e explorando politicamente os estudantes e, ainda, violam o regime democrático ao favorecer um posicionamento político em relação ao demais, bem como violam o que seria ensinado pelos pais no ambiente familiar sobre educação moral (SENADO FEDERAL, 2016).

Outra justificativa usada para a aprovação do Programa ESP é a estigmatização de certas visões ideológicas e políticas, o que favoreceria a ocorrência de bullying nas escolas - com significativo risco de sofrer isolamento, tratamentos hostis, e até mesmo agressões físicas -, que seriam praticados pelos próprios estudantes, mas também pelos professores (SENADO FEDERAL, 2016; MALTA, 2018).

Essas afirmativas, no entanto, não são baseadas em estudos científicos, mas simplesmente nas crenças dos apoiadores do Programa ESP e em alguns depoimentos disponíveis no site ESP, o que, certamente, não correspondem à realidade da educação brasileira. Nas palavras de Fernando Penna (2016, p. 100), “a estratégia aqui, como nos outros casos, é utilizar alguns casos particulares, onde a questão pode ter sido malconduzida por um professor, para proibir a discussão de toda uma temática central ao entendimento da realidade na qual estamos 
inseridos".

Conforme as palavras de Magno Malta, o autor desse projeto, em vídeo disponível em seu canal no Youtube, "a escola não é nada mais nada menos que o lugar que abre janela para o conhecimento" e que "quem educa é pai e mãe" (MALTA, 2016). Em entrevista realizada em 2018, também disponível no Youtube, o ex-senador afirma que "o professor, no máximo, tem que ensinar matemática, português”, além disso, ele dá especial atenção à questão da ligação de professores a sindicatos, chamando-os de "militância de professores ideológicos" e afirma que os mesmos têm como objetivo "criar uma geração de pessoas que pudesse estar debaixo do domínio ideológico deles" e de "recrutar adolescentes e crianças para fazer um outro exército socialista, um outro exército comunista [...]” (MALTA, 2018).

Além dessas declarações, Magno Malta também afirma “o que nós temos hoje no Brasil, a partir desses 13 anos desse governo que está sendo afastado governo Dilma Rousseff, é uma pregação ideológica, partidária, política e de religião" e que: "o processo eleitoral tá aí e nós já sabemos qual é o interesse deles, depois de ter assaltado a nação, roubado a nação, mentido à nação e perdido aquele nicho que eles tinham de votos, eles agora querem criar uma outra geração que vote neles", referindo-se a políticos de esquerda (MALTA, 2016; MALTA, 2018).

Em linhas gerais, observa-se que Magno Malta adota no PL uma postura antidemocrática, não levando em consideração que a escola, como espaço público, é um local de pluralidade. Ademais, evidencia-se no Projeto de Lei uma tática de deturpação da realidade, utilizando-se até mesmo a Constituição Federal, a Convenção Americana de Direitos Humanos e o Estatuto da Criança e do Adolescente de maneira descontextualizada, com o intuito de camuflar as reais intenções ao tentar implantar o Programa Escola sem Partido.

Conforme os trâmites legais do Senado Federal, o Projeto de Lei Escola sem Partido chegou à relatoria para ser apreciado e analisado pelo então Senador pelo Partido Popular Socialista (atualmente chamado de Cidadania) Cristovam Buarque. Sendo assim, o relator sugeriu a rejeição do PL 193/2016 pelo Senado, pois entendeu que "participação, diálogo e crítica são elementos do processo educativo essenciais para diferenciar a verdadeira educação da mera doutrinação" e acrescentou que o professor "deve ter liberdade para orientar os alunos no caminho da autonomia moral e intelectual, nunca no rumo da submissão" (BUARQUE, 2017, p. 7). No relatório, o então Senador Cristovam Buarque recordou o método socrático do diálogo em busca da verdade e lembra que o próprio Sócrates foi acusado injustamente de corromper a juventude ateniense e, por essa razão, foi condenado (BUARQUE, 2017). Frente a isso, o autor do PL 193/2016, Magno Malta, o retirou de tramitação em novembro de 2017, mas continua a apoiar outros PLs semelhantes e a difundir o Movimento Escola Sem Partido em suas redes sociais (MALTA, 2017).

Portanto, o que se pode concluir a respeito da proposta de implantação do Programa Escola Sem Partido feita por Magno Malta é que, na realidade, não se trata de evitar ou eliminar a partidarização no ambiente escolar, mas de extinguir o livre pensamento por parte dos professores e a sua expressão, bem como acabar com a possibilidade de desenvolvimento do pensamento crítico entre os alunos, com o objetivo de impossibilitar a problematização de questões atuais e a democratização da escola, além de facilitar a demonização de ideias supostamente de esquerda (MANHAS, 2016, p 79). 


\section{CONSIDERAÇÕES FINAIS}

É preciso reconhecer que um projeto de lei, proposto por um senador da república totalmente ligado a reprodução de valores tradicionais antidemocráticos, que tinha como inspiração principal a luta de um movimento social conservador, afetaria o espaço público escolar de forma impactante. A história do nosso país, que escravizou em sua essência, provou que as iniciativas públicas que visam a ascensão da diversidade são combatidas. Durante muito tempo, a Igreja Católica operou seu monopólio, garantindo a promoção de sua fé e de pautas de seu interesse, especialmente na educação.

Depois de longo período, em um momento que o Brasil tinha condições favoráveis de fomentar uma educação que representasse a totalidade de seu povo, outro grupo majoritário impôs suas ideias, que se transformaram em movimento social, reproduzindo valores que implicaram na estigmatização de culturas e modos de vida. Tudo isso foi possível, assim como muitas vezes no Brasil, através do meio político, espaço de poder ocupado majoritariamente ainda hoje por sujeitos que representam interesses próprios ou interesses de grupos hegemônicos.

Por outro lado, ainda existem grupos sociais organizados, que lutam em defesa de instituições públicas, como a escola. Essa luta, não possui o objetivo de exterminar posições contrárias ou de declarar guerra no meio social. Ao contrário disso, o que se busca é a promoção de um espaço verdadeiramente público em sua essência, onde as variadas visões de mundo, as inúmeras crenças e as infinitas culturas são respeitadas, desde que não tenham cunho fascista. Dessa forma, vimos que o próprio Senado Federal, instituição pública que deve atender interesses que garantam o bem-estar coletivo, posicionou-se contrário ao projeto de lei Escola Sem Partido, através da atuação do seu relator e de demais políticos. Não se pode esquecer também que a atuação de grupos sociais compostos por professores, alunos, artistas e simpatizantes contra o projeto de lei foi de suma importância, pois demonstrou a força da democracia, que apesar de nova, resiste dia após dia para não ser enfraquecida.

Em decorrência dessa resistência, como já foi dito, Magno Malta entrou com pedido para que o projeto de lei de sua autoria fosse arquivado. Contudo, é preciso admitir que esse fato não indica que o então senador reconheceu que seu projeto possuía caráter autoritário. Longe disso, a desistência do projeto de lei representou uma estratégia do então político, que ao ver que sua proposta não seria aprovada, preferiu auxiliar outros colegas a aprovarem propostas de cunho idêntico que não param de ser materializadas em proposta/alteração de lei em várias casas legislativas espalhadas no Brasil, como por exemplo, na Câmara dos Deputados. Por hora, a derrota do Projeto de Lei Escola sem Partido no senado representa uma vitória expressiva da democracia, já que garantiu que a LDB, lei norteadora da Educação Nacional, não sofresse inclusões de caráter arbitrário.

Em análises finais, é imprescindível que se observe que o atual cenário político brasileiro é um campo favorável para que ideias radicais sejam transformadas em ataques diretos a uma educação plural. Tornam-se evidentes esses ataques ao percebermos que o atual ministro da educação Abraham Weintraub, escolha chancelada pelo Presidente da República, é simpatizante de movimentos como o Escola Sem Partido, além de declarar abertamente guerra às universidades públicas. Para reverter essa problemática, é indispensável que a sociedade pela expressão de sua pluralidade, através da luta e resistência dê ênfase no bem comum para que os direitos conquistados na educação no decorrer dos anos não sejam perdidos. 


\section{REFERÊNCIAS}

AGÊENCIA SENADO. Magno Malta. 2015. Disponível em: <https://www12.senado. leg.br/noticias/materias/2015/01/30/magno-malta $\geq$. Acesso em: 22 de agosto de 2019. AGÊNCIA SENADO. Marcado por polêmicas, projeto que criminaliza homofobia depende da votação do novo Código Penal. 2014. Disponível em: <https://www12.senado.leg.br/noticias/materias/2014/09/05/marcado-por-polemicas-projeto-que-criminaliza -homofobia-depende-da-votacao-do-novo-codigo-penal>. Acesso em: 25 de agosto de 2019. BARDIN, Laurence. Análise de conteúdo. Lisboa: Edições 70, 2002.

BONAVIDES, Paulo; AMARAL, Roberto. Textos políticos da história do Brasil. Brasília: Senado Federal, Subsecretaria de Edições Técnicas, 1996.

BRASIL.Constituição da República dos Estados Unidos do Brasil. 1891. Disponível em: <http://www.planalto.gov.br/ccivil_03/constituicao/Constituicao91.htm>. Acesso em 28 de agosto de 2019.

BUARQUE, Cristóvam. Parecer da Comissão de Educação, Cultura e Esporte sobre o Projeto de Lei do Senado $\mathbf{n}^{\circ} 193$ de 2016, do senador Magno Malta. 2017. Disponível em: <https:/ / legis.senado.leg.br/sdleg-getter/documento?dm=7268020\&disposition=inline $>$. Acesso em: 29 de agosto de 2019. CARREIRA, Denise. No chão da escola: Conversando com famílias e profissionais da educação sobre o Escola Sem Partido. Ação educativa, Assessoria, Pesquisa e Informação (Org.). A ideologia do movimento "Escola Sem Partido, v. 20, p. 125-136, 2016.

CUNHA, Clera Barbosa; BARBOSA, Cláudia. O ensino religioso na escola pública e suas implicações em desenvolver o senso de respeito e tolerância dos alunos em relação aos outros e a si próprios. Sacrilegens, Juiz de Fora, v.8, n.1, p.164-181, dez/2011

E-CIDADANIA. Consulta Pública: PLS 193/2016. Disponível em: <https://www12.senado.leg.br/ecidadania/visualizacaomateria?id=125666>. Acesso em: 5 de junho de 2019. EDUCATIVA, Ação. A Ideologia do Movimento Escola Sem Partido: 20 autores desmontam o discurso. São Paulo: Ação Educativa, 2016.

ES elege Ferraço e Malta para o senado. G1 - O Portal de notícias da Globo, São Paulo, 03 de out. de 2010. Disponível em: <http://g1.globo.com/especiais/eleicoes-2010/noticia/2010/10/es-ele ge-ferraco-e-malta-para-o-senado.html $\geq$. Acesso em: 01 de setembro de 2019.

ES elege Fabiano Contarato e Marcos Do Val para o Senado. G1 - O Portal de Notícias da Globo, Espírito Santo, 07 de out. de 2018. Disponível em: <https://g1.globo.com/es/espirito-santo/eleicoes/2018/noticia/2018/10/07/es-elege-fabiano-contarato-e-marcos-do-val-

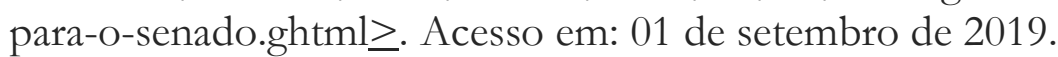

ESP - ESCOLA SEM PARTIDO. Objetivos; Apresentação; Quem somos. 2017. Disponível em: <http://www.escolasempartido.org/quem-somos>. Acesso em 20 de maio de 2019. FEDERAL, Senado. Lei de Diretrizes e Bases da Educação Nacional. Brasília, 2005. FERREIRA, Walace; ALVADIA FILHO, Alberto. A serpente pedagógica: o projeto escola sem partido e o ensino de sociologia no Brasil. e-Mosaicos, v. 6, n. 12, p. 64-80, 2017. FONSECA, Alexandre Brasil. Secularização, pluralismo religioso e democracia no Brasil: um estudo sobre a participação dos principais atores evangélicos na política (19982001). São Paulo: Tese de Doutorado em Sociologia, Faculdade de Filosofia, Letras e Ciências Humanas, Universidade de São Paulo (USP), 2002.

FREIRE, Paulo. Pedagogia da autonomia: saberes necessários à prática educativa. São 
Paulo: Paz e Terra, 1996.

FRESTON, Paul Charles. Protestantes e Política no Brasil: da Constituinte ao Impeachment. São Paulo: Doutorado em Ciências Sociais, Universidade Estadual de Campinas (UNICAMP), 1993.

FUNDAÇÃO GETÚliO VARGAS (FGV) - Centro de Pesquisa e Documentação de História Contemporânea do Brasil. MALTA, Magno. 2015. Disponível em: <http://www.fgv. $\mathrm{br} / \mathrm{cpdoc} /$ acervo/dicionarios/verbete-biografico/malta-magno $\geq$. Acesso em: 23 de agosto de 2019.

GRUMAN, Marcelo. O lugar da cidadania: Estado moderno, pluralismo religioso e representação política. Revista de Estudos da Religião, n. 1, p. 95-117, 2005.

GUILHERME, Alexandre Anselmo; PICOLI, Bruno Antonio. Escola sem Partido-elementos totalitários em uma democracia moderna: uma reflexão a partir de Arendt. Revista Brasileira de Educação, v. 23, e230042, 2018.

MALTA, Magno. Escola Sem Partido na visão da Ciência Política. 2018. Disponível em: <https: / /www.youtube.com/watch?v=625rQWjeYpc $>$. Acesso em: 05 de junho de 2019.

MALTA, Magno. Escola Sem Partido. 2017. Disponível em: < https://www.youtube.com/ watch?v=E1bnZR_rlWA $>$. Acesso em: 05 de junho de 2019.

MALTA, Magno. Senador Magno Malta explica o Projeto Escola Sem Partido. 2016. Disponível em: <https://www.youtube.com/watch?v=jPlisetjT-s>. Acesso em: 05 de junho de 2019.

MANHAS, Cleomar. Nada mais ideológico que "Escola sem Partido". Ação educativa, Assessoria, Pesquisa e Informação (Org.). A ideologia do movimento "Escola Sem Partido, v. 20, p. 15-22, 2016.

MARIANO, Ricardo. Laicidade à brasileira. Católicos, pentecostais e laicos em disputa na esfera pública. Civitas-Revista de Ciências Sociais, v. 11, n. 2, 2011.

MARIANO, Ricardo. Mudanças no campo religioso brasileiro no censo 2010. Debates do NER, Porto Alegre, ano 14, n. 24, p. 119-137, jul./dez. 2013

MORAES, Roque. Análise de conteúdo. Revista Educação, Porto Alegre, v. 22, n. 37, p. 7 32, 1999.

PENNA, Fernando. O ódio aos professores. Ação educativa, Assessoria, Pesquisa e Informação (Org.). A ideologia do movimento "Escola Sem Partido", v. 20, p. 93-100, 2016.

PY, Fábio; REIS, Marcos Vinicius de Freitas. Católicos e evangélicos na política brasileira. Estudos de Religião, v. 29, n. 2, p. 135-161, 2015.

SARAIVA, Karla; VARGAS, Juliana Ribeiro. Os perigos da Escola sem Partido. Revista Teias, v. 18, n. 51, p. 68-84, 2017.

SENADO FEDERAL, Portal do. Magno Malta - atividade legislativa. Disponível em:

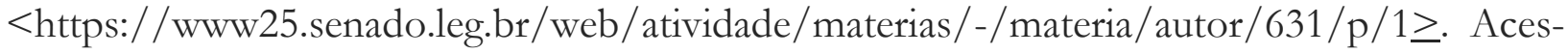
so em: 27 de agosto de 2019.

SENADO FEDERAL, Portal do. Perfil do senador Magno Malta. Disponível em: <https://www25.senado.leg.br/web/senadores/senador/-/perfil/631>. Acesso em: 17 de agosto de 2019

SENADO FEDERAL, Portal do. Projeto de Lei do Senado no 193, de 2016. 2016. Acesso em 22 de maio de 2019. 